\title{
EVERYTHING IS SELF-EVIDENT
}

\section{Steven DIGGIN}

\begin{abstract}
Plausible probabilistic accounts of evidential support entail that every true proposition is evidence for itself. This paper defends this surprising principle against a series of recent objections from Jessica Brown. Specifically, the paper argues that: (i) explanationist accounts of evidential support convergently entail that every true proposition is self-evident, and (ii) it is often felicitous to cite a true proposition as evidence for itself, just not under that description. The paper also develops an objection involving the apparent impossibility of believing $\mathrm{P}$ on the evidential basis of $\mathrm{P}$ itself, but gives a reason not to be too worried about this objection. Establishing that every true proposition is self-evident saves probabilistic accounts of evidential support from absurdity, paves the way for a non-sceptical infallibilist theory of knowledge and has distinctive practical consequences.
\end{abstract}

KEYWORDS: evidence, reasons, basing relation

I used to get annoyed in abstract discussions to hear men tell me: 'You think such and such a thing because you are a woman.' But I know that my only defence is to answer, 'I believe it because it is true'...

BEAUVOIR $^{1}$

We form, maintain and revise beliefs on the basis of our evidence. When we do so, the true propositions ${ }^{2}$ which are our evidence justify our beliefs. These true

\footnotetext{
${ }^{1}$ Simone de Beauvoir, Extracts from The Second Sex, trans. Constance Borde and Sheila MalovanyChevallier (London: Vintage Books, 2016), 6.

2 This paper assumes a non-mentalist, factualist ontology of evidence-primarily because this is a crucial presupposition of the existing debate between Timothy Williamson and Jessica Brown. For a fairly recent overview of the landscape of the debate concerning the ontology of evidence, see Kurt Sylvan, “Epistemic Reasons I: Normativity,” Philosophy Compass 11 (2016): 364-376. The Self-Evidence principle which I defend in this paper plays an interesting role in this debate; for instance, Bob Beddor ("Prospects for Evidentialism," in The Routledge Handbook of the Philosophy of Evidence, eds. Maria Lasonen-Aarnio and Clayton Littlejohn (New York: Routledge, forthcoming)) uses a version of this principle to argue against a mentalist ontology of evidence, whereas John Turri ("The Ontology of Epistemic Reasons," Nous 43 (2009): 490-512) appeals to considerations related to Self-Evidence on order to argue against a propositionalist (and a fortiori, factualist) ontology of evidence. I take no specific stance in this paper on how the Self-Evidence principle should affect the ongoing debate about the ontology of evidence; the point is just to show that, on a factualist view of evidence, true propositions are self-evident. Thanks to an anonymous
} 


\section{Steven Diggin}

propositions are often distinct from the (possibly false) propositions for which they are evidence. For instance, one's belief that a trash bag will soon be in the basement might be evidentially justified by the true proposition that she just dropped it down the garbage chute. However, it is not obvious that a true proposition which is evidence must always be distinct from the proposition for which it is evidence. One case in which a true proposition might be evidence for itself is when its truth is directly introspectable. For instance, the true proposition that she is in pain might be all the evidence that an agent has for believing that she is in pain.

A more surprising suggestion is that every true proposition is evidence for itself:

Self-Evidence: For any true proposition $\mathrm{P}, \mathrm{P}$ is evidence that $\mathrm{P}$ is true. ${ }^{3}$

This principle says that true propositions are self-evident in an objective sense. A true proposition $\mathrm{P}$ is evidence that $\mathrm{P}$ in the sense of providing an objective epistemic reason to believe $\mathrm{P}$, regardless of whether anyone actually possesses this reason as such. In other words, true propositions are self-evident without necessarily being self-evident for any agent. However, once an agent possesses a proposition $\mathrm{P}$ as evidence (for the purpose of this paper, I will take knowing $\mathrm{P}$ to be sufficient for possessing $\mathrm{P}$ as evidence) ${ }^{4}$ then $\mathrm{P}$ will also become subjectively self-evident, in the sense of being an epistemic reason which this agent possesses for believing $\mathrm{P}$.

The most prominent defender of Self-Evidence is Timothy Williamson. ${ }^{5}$ Williamson sees Self-Evidence as a surprising consequence of a general probabilistic

reviewer on a previous version of this paper for pressing me to clarify this.

${ }^{3}$ There may be some exceptions to this generalisation. For instance, Timothy Williamson, Knowledge and its Limits (Oxford: Oxford University Press, 2000, 188) argues that some true propositions (e.g., tautologies) cannot be evidence for anything, and therefore cannot be selfevident either. I will not be concerned with possible exceptions to Self-Evidence in this paper.

${ }^{4}$ See, for example, John Hyman, "How Knowledge Works," Philosophical Quarterly 49 (1999): 433-451; Williamson, Knowledge and its Limits, 184-208. Actually, following Errol Lord, The Importance of Being Rational (Oxford: Oxford University Press, 2018), I think that one can possess a true proposition as evidence even if she is only in a position to know this proposition. This makes sense of how certain truths, e.g., simple mathematical and moral truths, are subjectively selfevident (for anyone) even though people have not yet come to believe (and so, know) them. That is, since any agent (perhaps, with an adequate conceptual repertoire) is necessarily in a position to know these truths, then any agent already possesses these truths as self-evident.

Several writers have also argued that, in order to possess a true proposition $\mathrm{P}$ as a reason to believe another proposition $\mathrm{Q}$ one must also treat or conceive of $\mathrm{P}$ as a reason to believe $\mathrm{Q}$ (see Lord, Importance of Being Rational, 97-124 and references therein). I will not be concerned with a potential treating condition on reason-possession in the present paper.

${ }^{5}$ Williamson, Knowledge and its Limits, 187-8; see also Timothy Williamson, "E=K, but what 
approach to evidential support. On standard versions of this approach, one proposition is evidence (for some agent) ${ }^{6}$ to believe another proposition exactly when the probability (on an agent's total background evidence) of the truth of the latter proposition conditional on the former is greater than its unconditional probability (or alternatively, as long as the conditional probability is above a certain threshold). That is, for any propositions $\mathrm{P}$ and $\mathrm{Q}$ and a subjective probability function $\operatorname{Pr}($.$) :$

$\mathrm{P}$ is evidence that $\mathrm{Q}$ iff $\operatorname{Pr}(\mathrm{Q} \mid \mathrm{P})>\operatorname{Pr}(\mathrm{Q})^{7}$

The probability of the truth of any proposition conditional on itself is always 1 (as long as its unconditional probability is nonzero). Therefore, as a limiting case of evidential support, any true proposition which is evidence for anything provides maximal evidential support for itself. Moreover, this entailment cannot be plausibly blocked by adding conditions to the simple probabilistic account. ${ }^{8}$ For instance, simply declaring that no proposition $\mathrm{P}$ is evidence for itself does not rule out the entailment that $P \& Q$ (for any arbitrary $Q$ ) is also perfect evidence that $P$.

For the most part, this surprising result has been greeted with an incredulous stare. It may seem deeply counterintuitive, and perhaps even circular, ${ }^{9}$ that any true proposition can be evidence for itself-let alone that every true proposition is. Williamson's response is to point out that counterintuitive results are often entailed

about R?," in The Routledge Handbook of the Philosophy of Evidence, eds. Lasonen-Aarnio and Littlejohn.

${ }^{6}$ It is worth noting that a true proposition can be evidence for a particular agent (i.e., relative to her existing background evidence) even if she does not possess this truth as evidence. That is, the distinction between agent-neutral and agent-relative epistemic reasons does not align with the possessed/unpossessed distinction. However, since true propositions are always objectively selfevident relative to any agent's background evidence, I will not be concerned with the agentneutral/agent-relative evidence distinction here.

7 The unconditional probability of $\mathrm{Q}$ in this formula is the probability of the truth of the proposition 'prior to investigation' (Williamson, Knowledge and its Limits, 211). This is why, even though the probability of every true proposition conditional on itself is always 1 , the unconditional probability of (almost) any non-tautological proposition is less than 1 (and therefore why conditioning this proposition on itself raises the probability of its truth).

${ }^{8}$ See Jessica Brown, "Evidence and Epistemic Evaluation," in Oxford Studies in Epistemology, Vol. 5, eds. Tamar Szabó Gendler and John Hawthorne (Oxford: Oxford University Press: 2015), 44-54. 9 This charge of circularity, which often arises in conversation, is misguided (at least, given the present factualist ontology of evidence). Self-Evidence does not entail that all true propositions are 'self-justifying' in some objectionable sense. True propositions justify beliefs, not true propositions. However, if we understand evidence on a mentalist view (for instance, where evidence is constituted by beliefs rather than true propositions), then the circularity charge might be appropriate. 
by our simplest and best logical and mathematical theories; for instance, "[c]ommon sense did not want 0 to be a number; it did not want a contradiction to entail everything; it did not want an axiom to have a one-line proof consisting of just the axiom itself." 10 Just like these cases, Self-Evidence is an instance where our best theoretical frameworks are better guides to truth than educated common sense.

Actually, it is not even clear that Self-Evidence is very counterintuitive. Many (perhaps even most) epistemologists accept a version of the Truth-Norm of Belief: Believe $P$ (if and) only if $P$ is true. Since valid norms are in the business of providing normative reasons, then it is natural to see the Truth-Norm of Belief as entailing that, for any proposition P, P's truth is an objective epistemic reason to believe P. In other words, the extremely intuitive principle that "truth is the aim of belief" plausibly entails that the Self-Evidence principle is valid.

However, Jessica Brown has recently emerged as a vocal opponent of SelfEvidence. ${ }^{11}$ She has advanced two specific objections against the principle:

(1) Non-Convergence: Self-Evidence is a formal artefact of the probabilistic approach to evidential support, which is not entailed by other prominent approaches. ${ }^{12}$

(2) Infelicity: It is almost always infelicitous to cite a true proposition as evidence for itself; moreover, this infelicity cannot be explained away pragmatically. ${ }^{13}$

Both of these objections fail. Or so this paper argues. I also clarify a third possible objection to Self-Evidence involving the (im)possibility of believing $\mathrm{P}$ on the basis of the true proposition $\mathrm{P}$ (building on some of Brown's discussion). It is beyond the scope of this paper to resolve this final objection, but I give a reason not to be too worried about it at present.

$\S 1$ shows that the most prominent alternative approach to evidential support convergently entails that every true proposition is self-evident. $§ 2$ argues that it is often felicitous to cite a proposition as evidence for itself, just not under that description. §3 raises a potential problem involving the combination of SelfEvidence and a prominent version of the Ought Implies Can principle, and briefly explores a direction for resolving this problem. Every true proposition really is selfevident (including this one). $\$ 4$ briefly discusses the philosophical and practical significance of this conclusion.

10 Williamson, "E=K."

11 See Jessica Brown, "Infallibilism, Evidence and Pragmatics," Analysis 73 (2013): 626-35;

Fallibilism, Evidence and Knowledge (Oxford: Oxford University Press, 2018) 45-66; and "Evidence and Epistemic Evaluation".

12 Brown, "Infallibilism," 628.

${ }^{13}$ Brown, "Infallibilism," 628-32; Brown, Fallibilism, 53-60. 


\section{1. (Non-)Convergence}

Self-Evidence is a surprising entailment of the probabilistic approach to evidential support. This might be seen as a reason to accept Self-Evidence, but it can also be taken as a reductio of that approach. In other words, if probabilistic accounts of evidential support uniquely entail the counterintuitive Self-Evidence principle, then it might be rational to abandon these accounts in favour of their main competitors. Brown suggests that probabilistic accounts are unique in entailing Self-Evidence, and she thereby implies that the principle is just an implausible formal artefact of a misguided philosophical theory. ${ }^{14}$ On the other hand, if several distinct approaches to evidential support independently converge in entailing the truth of Self-Evidence, then this is strong evidence in favour of the principle. This section argues that, contrary to Brown's suggestion, the most prominent competing approach to evidential support also entails that, as a limiting case, every true proposition is selfevident.

The main alternative to the probabilistic approach seeks to ground evidential support on explanatory connections between propositions. ${ }^{15}$ This explanationist approach standardly emphasises the role of Inference to the Best Explanation (IBE) in scientific practice and everyday scenarios. On a basic understanding, IBE says that one true proposition $\mathrm{P}$ is evidence (for some agent) to believe another proposition $\mathrm{Q}$ as long as $Q$ is part of Best Explanation ${ }^{16}$ (on the agent's total background evidence) for why $\mathrm{P}$ is true. As Brown points out, true propositions are generally not selfexplanatory; so if IBE is all there is to the explanationist approach to evidential support, then this approach does not entail Self-Evidence.

However, as a general account of evidential support, this basic version of the explanationist approach is obviously inadequate. First, the simple account cannot explain how we gain justified beliefs about simple logical consequences of known propositions; for instance, forming a justified belief that there are four animals in

\footnotetext{
${ }^{14}$ Brown, "Infallibilism," 628.

${ }^{15}$ See, for instance, Earl Conee and Richard Feldman, "Evidence," in Epistemology: New Essays, ed. Quentin Smith (Oxford: Oxford University Press: 2013); Kevin McCain, Evidence and Epistemic Justification (London: Routledge: 2014). Brown ("Infallibilism," 628) also mentions a Hempelian Hypothetico-Deductive account of evidential support, which analyses evidential support in terms of logical entailment from observables. The requirement that evidence be observable prevents unobservable true propositions being evidence for themselves, so this account does not entail (universal) Self-Evidence. However, the observable/unobservable distinction is notoriously problematic and, in any case, Hypothetico-Deductivism is no longer a prominent approach to evidential support.

${ }^{16}$ That is, the explanation which scores highest (and perhaps also "high enough") with respect to the explanatory virtues, i.e., simplicity, coherence, unification, etc.
} 


\section{Steven Diggin}

one's garden on the basis of the evidence that there are two squirrels and two birds. ${ }^{17}$ Second, the account cannot explain how we can have justified beliefs about many events in the near future, such as whether the golf ball which an agent just putted will go into the hole. ${ }^{18}$

There are several improved explanationist accounts available, the most prominent of which has recently been developed by Kevin McCain. ${ }^{19}$ This account develops the basic IBE version of the explanationist approach in two separate ways. First, McCain argues that a proposition $\mathrm{P}$ can be evidence for another proposition $\mathrm{Q}$ as long as $\mathrm{Q}$ is a logical entailment of $\mathrm{P}$ (and the agent for whom it is evidence is appropriately sensitive, in some sense, to this logical connection). ${ }^{20}$ Second, he argues that, just as we make inferences backwards along an explanatory chain via IBE, we can also make inferences forwards along an explanatory chain. ${ }^{21}$ For instance, an agent can infer from the fact that she putted the golf ball in a certain way that it will go into the hole, since it goes into the hole because of how she putted it. Call this, Inference to the Best Explanatory Consequence (IBEC). This development of the basic explanationist approach says that a true proposition $\mathrm{P}$ can be evidence (for some agent) to believe another proposition $\mathrm{Q}$ as long as $\mathrm{P}$ would give a Better Explanation (on her total background evidence) of the truth of $Q$ than of its falsity. ${ }^{22}$

Since every true proposition obviously logically entails itself, the first of these developments is sufficient to ensure that Self-Evidence is true. However, this simple argument does not give a satisfying explanation for why Self-Evidence is entailed by the explanationist approach, nor does it show that the principle obtains specifically as a limiting case of evidential support (as on the probabilistic approach). Therefore, there is scope for seeing this as a mere coincidence rather than as genuine

\footnotetext{
${ }^{17}$ See, for instance, Alvin Goldman, "Toward a Synthesis of Reliabilism and Evidentialism? Or: Evidentialism's Troubles, Reliabilism's Rescue Package," in Evidentialism and Its Discontents, ed. Trent Dougherty (Oxford: Oxford University Press: 2011).

${ }^{18}$ See T. Ryan Byerly, "Explanationism and Justified Beliefs about the Future," Erkenntnis 78 (2013): 229-243.

${ }^{19}$ See especially McCain, Evidence and Epistemic Justification; Kevin McCain, "Explanationism: Defended on All Sides," Logos \& Episteme 6 (2015): 333-349. McCain's explanationist account is mentalist, in the sense that he takes an agent's evidence to be constituted by her non-factive mental states rather than true propositions. However, it is straightforward to construct a factualist version of McCain's account, which remains true to many of the motivations behind his proposal.

${ }^{20}$ McCain, Evidence and Epistemic Justification, 64-8.

${ }^{21}$ Compare, "upwards" and "downwards" inferences in Nevin Climenhaga, "Evidence and Inductive Inference," in The Routledge Handbook of the Philosophy of Evidence, eds. LasonenAarnio and Littlejohn.

${ }^{22}$ McCain, "Explanationism," 339.
} 
convergence. However, the second development of the basic explanationist account plugs this gap, by specifically illustrating why the Self-Evidence principle obtains as a limiting case of evidential support.

Once we recognise that we can infer both backwards and forwards along an explanatory chain, then we can combine the two sorts of inference to undergird a single evidential support relation. For instance, on the background assumption that there is a causal connection between parent/child smoking behaviour, an agent could use IBE to infer from the fact that X smokes to the proposition that X's father smoked, and then infer via IBEC to the conclusion that X's siblings also smoke. ${ }^{23} \mathrm{In}$ other words, it is standardly accepted that one true proposition can be evidence for another proposition when they have a common explanation (and the agent for whom it is evidence is appropriately sensitive to this explanatory connection). However, it is trivially true that every true proposition has a common explanation with itself. Therefore, the very same reasoning which showed that the fact that $\mathrm{X}$ smokes is evidence that X's siblings smoke also establishes that the true proposition that $\mathrm{X}$ smokes is evidence that $\mathrm{X}$ smokes.

Although this shows that true propositions are evidence for themselves, it is not immediately clear how strong this evidential support relation is. For instance, in the example above, the proposition that $\mathrm{X}$ smokes is not (much) stronger evidence for itself than it is for the proposition that X's siblings smoke. In other words, on this version of the explanationist approach, the strength of any proposition $\mathrm{P}$ as evidence for itself is determined by the 'goodness' of the explanatory connection (on some agent's background evidence) between $\mathrm{P}$ and some other proposition $\mathrm{Q}$. This looks like a strange result, since by choosing a proposition $\mathrm{Q}$ which gives an arbitrarily good (or bad) explanation of $\mathrm{P}$, it seems that $\mathrm{P}$ can be arbitrarily strong (or weak) evidence for itself. However, by looking at the deeper motivation behind the explanationist approach, we can see why the limiting case of this procedure entails that every true proposition maximally evidentially supports itself, just like on the probabilistic approach.

Recall that Brown's initial suggestion was that, on explanationist accounts of evidential support, true propositions cannot be evidence for themselves since they do not explain themselves. In other words, if explanationist accounts seek to ground evidential connections directly on the explanation relation, then because explanation is not a reflexive relation, Self-Evidence cannot be true. However, this is a mischaracterisation of the explanationist approach. The basic idea is not that any true proposition which is evidence for another proposition must explain why the latter is true, but rather the weaker claim that there must be an explanatory

${ }^{23}$ Compare, "sideways" inferences in Climenhaga, "Evidence and Inductive." 


\section{Steven Diggin}

connection between the two propositions. Moreover, although explanation is not a reflexive relation, explanatory connectedness plausibly is. That is, since explanatory connections run both backwards and forwards, then every true proposition which explains or is explained by anything is necessarily explanatorily connected to itself. ${ }^{24}$ This can be known a priori (and agents are plausibly already implicitly aware of it). Therefore, on any agent's background evidence, there is a guaranteed explanatory connection between any true proposition and itself, so any true proposition (which the agent possesses as evidence) provides maximal evidential support for itself. In sum, just like the probabilistic approach, adequate versions of the explanationist approach to evidential support convergently entail that, as a limiting case, every true proposition is self-evident.

\section{2. (In)Felicity}

Notwithstanding this convergence, Brown thinks that she has a knockdown objection against Self-Evidence. This is simply the observation that, except for certain special cases, ${ }^{25}$ it is always infelicitous to cite a proposition as evidence for itself. For instance, she writes that:

...if Morse is asked for his evidence that Burglar Bill was in the vicinity of the Central Jewellery Store at the time of the heist, it is infelicitous for him to reply by saying 'Burglar Bill was in the vicinity of the Central Jewellery Store at the time of the heist. ${ }^{26}$

Moreover, Brown argues extensively that this infelicity cannot be explained away by appeal to Gricean maxims, conversational norms or other pragmatic phenomena. ${ }^{27}$ Therefore, the infelicity of citing a true proposition as evidence for itself can only be explained by the falsity of the Self-Evidence principle.

It is not necessary to challenge these specific arguments here, except to note that this general style of argument tends not to be very convincing for those who

\footnotetext{
${ }^{24}$ More formally, the reflexivity of the explanatory connectedness relation is entailed by the fact that this relation is symmetric and transitive, combined with the platitude that every true proposition has some explanation (or explains something). This is not to say that the evidential support relation is symmetric and transitive, since explanatory connectedness is necessary but not sufficient for evidential support on the explanationist approach. However, as I make clear in the main text, evidential support is reflexive, since the other jointly-sufficient conditions are met; most importantly, that the explanatory connection be the 'best' on the agent's background evidence.

25 These special cases include "self-verifying propositions, propositions concerning the nature of one's experiences, obvious logical truths, simple analytic truths, and so on" (Brown, Fallibilism, 51).

${ }^{26}$ Brown, Fallibilism, 51.

${ }^{27}$ Brown, "Infallibilism"; Brown, Fallibilism, 53-61.
} 
think that pragmatic explanations come very cheap. ${ }^{28}$ The more interesting point is that, even if Brown is correct that it is infelicitous for Morse to reassert a proposition as evidence for itself in the example above, this observation is argumentatively irrelevant.

In the example above (and in Brown's other examples), Morse is asked the specific question, 'What is your evidence for P?'. However, as Brown acknowledges ${ }^{29}$ it is dialectically open whether philosophers and non-philosophers alike are generally theoretically mistaken about the nature of evidence. That is, the proponent of Self-Evidence can accept that it is infelicitous to respond to a demand for evidence for $\mathrm{P}$ (under that description) by merely reasserting $\mathrm{P}$, but simply attribute this infelicity to a widespread misunderstanding about the nature of evidential support. In other words, citing a true proposition as evidence for itself (under that description) is like making other assertions which, although perfectly true, contravene common sense. For instance, compare the logician who infelicitously tells a naïve audience of non-philosophers that a contradiction entails everything.

Brown argues that this impasse must be resolved in favour of her explanation of the infelicity (i.e., that Self-Evidence is false) because this remains closer to the folk conception of evidential support-and moreover, the proponent of SelfEvidence can offer no independent evidence in favour of the alternative interpretation. ${ }^{30}$ This would be a weak argument even if the premises were true. However, it turns out that there is a strong piece of independent evidence in favour of the widespread-error interpretation of Brown's observed infelicity. It is actually often felicitous to cite a true proposition as evidence for itself, as long as it is not cited under that description.

Demands for an agent's evidence in shared reasoning allow us to answer two kinds of question. First, there is the explanatory question of why this agent actually believes a particular proposition P, i.e., which evidence or apparent evidence rationalises her belief. In other words, what are the reasons for which she believes $\mathrm{P}$. Second, there is the normative question of why the agent should believe P. That is, we are interested in what (possessed) reasons favour believing $P$, even if these reasons are not the ones which motivated the agent to believe $\mathrm{P}$ in the first place. It is important to keep these two kinds of question distinct, since $\S 3$ of this paper discusses a potential problem for the true proposition $\mathrm{P}$ being the reason for which

28 See, for instance, Jonathan Kvanvig, "Fallibilism: Evidence and Knowledge, by Jessica Brown." Mind 128 (2019), 1394.

${ }^{29}$ Brown, Fallibilism, 62.

30 Brown, Fallibilism, 62-3. 
one believes $\mathrm{P}$. Therefore, although I do think that one can cite a proposition $\mathrm{P}$ as evidence for itself in response to both the explanatory and normative questions, I will only discuss the normative question in this section.

The important point is just that, when we ask agents for their evidence for $\mathrm{P}$ by means of asking them what reasons favour believing $\mathrm{P}$, they can felicitously cite $\mathrm{P}$ as evidence for itself. For instance, consider the following simple dialogue:

MURDERER'S WIFE: Just give me one good reason to believe that my husband is the murderer!

HOLMES: Well, it's true! He is the murderer.

Obviously, Holmes is being uncooperative here. I think that his response is nevertheless a correct answer to this woman's question. It may also be apt, given the plausible background assumption that the wife will likely not accept alternative evidence which Homes could cite, for instance, the collection of unusual premises from which he made his brilliant and unconventional abduction. Therefore, although Holmes is not citing evidence which could rationally convince this person to change her mind, this does not mean that he is not giving a legitimate reason for believing. After all, it would be absurd for the murderer's wife to respond by saying, 'That's no reason at all to believe he's the murderer!.'

In fact, it seems (to me, at least) that, whenever one knows a particular proposition, one can correctly respond to a demand for one's reason for believing that proposition by simply (re)emphasising that it is true, although the uncooperativeness of this response would make it infelicitous in most conversational contexts. Nevertheless, there are a number of contexts in which, although one may also possess other evidence for believing a proposition $\mathrm{P}$, it is only appropriate to cite $\mathrm{P}$ as a reason to believe itself. ${ }^{31}$ For instance, there are plausibly cases of relatively unsophisticated agents who know a proposition $\mathrm{P}$ without having access to the grounds or method which they use for believing P. In particular, Srinivasan's recent portrait of an agent Nour, ${ }^{32}$ who is sensitive to the fact that a particular piece of behaviour was racist without having access to what exactly about the behaviour was racist, plausibly fits this bill. If someone demanded that Nour give a reason why they should believe that this behaviour was racist, it would be incorrect for her to say that she is not aware of any reason at all. Instead, what she should say (and what it

${ }^{31}$ However, there are also plausibly many other contexts where it is felicitous to cite multiple reasons for believing a proposition, one of which is that proposition's truth. For instance: "Why should anyone think that climate change is real?" "Because it is real - and also look at these scientific studies, etc."

32 Amia Srinivasan, "Radical Externalism," The Philosophical Review 129 (2020): 395-431. 
is felicitous for her to say), is that she does have a reason to believe that the behaviour was racist, namely the fact that (as she just knows) it was racist.

The overall lesson is that it can be felicitous to cite a true proposition $\mathrm{P}$ (or the proposition that $\mathrm{P}$ is true) as a reason to believe $\mathrm{P}$. One might concede this point, but reject the thesis that all reasons to believe $\mathrm{P}$ are evidence for $\mathrm{P}$. This thesis is plausibly false, since there can be practical reasons for belief; but there is no sense in which P's truth could be seen as a merely practical reason to believe P. Perhaps there is also a potential verbal dispute here; but an arbitrary restriction on the extension of the concept, 'evidence,' such that true propositions cannot be self-evident even though they can be epistemic reasons to believe themselves, would obviously be unattractive.

Therefore, contrary to Brown's central objection to Self-Evidence, it is often felicitous to cite a proposition $\mathrm{P}$ as evidence for itself, just not under that description. Moreover, if the above discussion is correct, then the (apparent) infelicity of responding to a demand for evidence by reasserting the claim under question just results from a misunderstanding. I think we would do well to become accustomed to citing propositions as self-evident, even under that very description.

\section{Basing}

Although she does not rely upon it in her case against Self-Evidence, Brown's discussion hints at a final objection. She tentatively proposes a positive account of evidential support which is supposed to explain why true propositions cannot be evidence for themselves. ${ }^{33}$ In brief, the suggestion is that one true proposition Q can be evidence for another proposition $\mathrm{P}$ only if it is possible for some agent to gain "first-time justification" for newly believing $\mathrm{P}$ on the basis of her evidence $\mathrm{Q}$. Brown's contention is that it is impossible for an agent to gain "first-time justification" for believing $\mathrm{P}$ on the basis of the true proposition $\mathrm{P}$ itself, and this is why true propositions can never be evidence for themselves. In particular, if an agent tried to infer $\mathrm{P}$ from the premise $\mathrm{P}$, then this inference would either be superfluous (since she already knew or believed that $\mathrm{P}$ ) or circular (since she had no independent basis to believe $\mathrm{P}$ in the first place). ${ }^{34}$ In neither of these cases would the agent gain first-time justification for believing P. Therefore, if the possibility of first-time justification is a necessary condition on what it takes for one proposition to be evidence for another, Self-Evidence must be false.

33 Brown, "Evidence and Epistemic Evaluation," 54-8; Fallibilism, 65n.11.

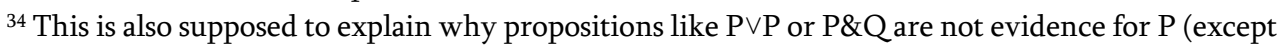
in special cases: see Brown, "Evidence and Epistemic Evaluation," 55-6). 
There is a straightforward way to further motivate and clarify this objection. A prominent version of the Ought Implies Can principle states that a true proposition can be a reason to do a particular thing only if it is possible for agents to do this thing on the basis of that reason..$^{35}$ For present purposes, this principle entails that the true proposition $\mathrm{P}$ can be an epistemic reason to believe (i.e., evidence for) $\mathrm{P}$ only if it is possible for agents to believe $\mathrm{P}$ on the basis of $\mathrm{P}$. However, this appears to be impossible. For instance, even moving away from the simplistic inferentialist picture of the epistemic basing relation which features in Brown's brief discussion, most standard accounts of the basing relation say that part of what it is for an agent to believe $P$ on the basis of her evidence $Q$ is for this agent's believing $Q$ to nondeviantly cause her to believe P. ${ }^{36}$ Since one cannot believe $\mathrm{P}$ because she believes $\mathrm{P}$, on pain of explanatory circularity (or having multiple beliefs with the same content), then it must be impossible to believe $\mathrm{P}$ on the basis of the reason $\mathrm{P} .{ }^{37}$ Thus, by this version of the Ought Implies Can principle, $\mathrm{P}$ cannot be a reason to believe itself. True propositions cannot be self-evident.

This is a powerful argument, and although one could challenge the relevant version of the Ought Implies Can principle, I think it is very plausible. It is beyond the scope of this paper to attempt to fully resolve this objection, but there is an important reason not to be too worried about it. The argument closely parallels the well-known No Guidance objection to the Truth-Norm of Belief. ${ }^{38}$ This objection says (roughly) that, although valid norms must be capable of guiding the behaviour which they purport to regulate, it would be impossible for a Truth-Norm to guide belief-formation in this way, because one would already need to believe $\mathrm{P}$ in order to be guided by the norm. However, although many philosophers recognise the force of the No Guidance objection, it seems that most have remained committed to the validity of the Truth-Norm even in the absence of a full resolution of the guidance problem. Even so, a number of potential solutions have been offered, which appeal,

\footnotetext{
${ }^{35}$ See Jonathan Way and Daniel Whiting, "Reasons and Guidance," Analytic Philosophy 57 (2016): 214-235, and the references cited therein.

${ }^{36}$ See, for instance, Keith Allen Korcz, "The Causal-Doxastic Theory of the Basing Relation," Canadian Journal of Philosophy 30 (2000): 525-550.

${ }^{37}$ Kevin McCain ("Epistemic Conservatism and the Basing Relation," in Well Founded Belief: New Essays on the Epistemic Basing Relation, eds. J. Adam Carter and Patrick Bondy (New York: Routledge, 2020): 201-214) points out that it is possible for one's believing P at time $t$ to cause her to continue to believe $\mathrm{P}$ at some later time, but (as he makes clear) this would not be sufficient for one to believe $\mathrm{P}$ on the basis of one's evidence P.

38 See especially, Kathrin Glüer and Åsa Wikforss, "Against Content Normativity," Mind 118 (2009): 31-70; Kathrin Glüer and Åsa Wikforss, "Against Belief Normativity." in The Aim of Belief, ed. Timothy Chan (Oxford: Oxford University Press, 2013).
} 
for instance, to the transparency of doxastic deliberation ${ }^{39}$ or to being indirectly guided by the Truth-Norm by means of complying with derivative evidentialist norms. ${ }^{40} \mathrm{I}$ think it is reasonable to suppose that the Self-Evidence principle and the Truth-Norm of Belief stand and fall together, so that if one of these strategies can successfully show that it is possible to be guided by the Truth-Norm of Belief, then it is plausible that this strategy can also show that it is possible to believe $\mathrm{P}$ (perhaps indirectly) on the basis of the reason P.

More specifically, a number of philosophers have argued that it is possible to believe a proposition $\mathrm{P}$ directly on the basis of the true proposition $\mathrm{P}$, for instance, in successful perception..$^{41}$ Although it remains conjectural, I suspect that a similar story could be told about inference, such that when one successfully infers a proposition $\mathrm{P}$ from her evidence $\mathrm{Q}$ (and thereby comes to know $\mathrm{P}$ ), she believes $\mathrm{P}$ on the basis of the true proposition $\mathrm{P}$ by means of believing $\mathrm{P}$ on the basis of $\mathrm{Q}$.

For now, all I will say in support of this conjecture is that, (returning to the discussion in \$2) just as people sometimes offer the true proposition $\mathrm{P}$ (or the truth of this proposition) as an epistemic reason to believe $\mathrm{P}$, it seems that they also sometimes cite $\mathrm{P}$ as the reason for which they believe P. For instance, this is how I read the passage from The Second Sex which is the epigraph to this paper. In juxtaposing (but also reconciling) the causal effect of being a woman on her beliefs with the rational responsiveness of these beliefs to the objective truth, Beauvoir is saying that the truth of what she believes is not (just) a cause of her belief, but rather the reason for which she believes. More generally, and in contrast to some philosophers, ${ }^{42}$ I see nothing absurd or especially problematic in the statement, "I believe $\mathrm{P}$ because (i.e., for the reason that) $\mathrm{P}$ is true." In particular, once we move away from a traditional belief-first model of the epistemic basing relation towards a the kind of competence account which has recently developed by Errol Lord and Kurt Sylvan, ${ }^{43}$ there is no obvious theoretical barrier to believing a true proposition $\mathrm{P}$ simply on the evidential basis of that very true proposition.

39 See Nishi Shah, "How Truth Governs Belief," The Philosophical Review 112 (2003): 447-482; Pascal Engel, "Doxastic Correctness," in The Aim of Belief, ed. Chan.

40 See especially, Ralph Wedgwood, "The Aim of Belief," Philosophical Perspectives 16 (2002): 267-97; Daniel Whiting, "Epistemic Worth," Ergo 7 (2020).

${ }^{41}$ See especially, Ian Schnee, "Basic Factive Perceptual Reasons," Philosophical Studies 173 (2016): 1103-1118; and also Jonathan Dancy, "Acting in the Light of Appearances," in McDowell and his Critics, eds. Cynthia Macdonald and Graham Macdonald (Oxford: Blackwell, 2006): 121-134.

42 See, for instance, John McDowell, "Response to Dancy," in McDowell and his Critics, eds. Macdonald and Macdonald, 134.

${ }^{43}$ Lord, Importance of Being Rational, 127-148; Errol Lord and Kurt Sylvan, "Prime Time (for the Basing Relation)," in Well Founded Belief, eds. Carter and Bondy, 141-174. 
Steven Diggin

However, I leave it to another occasion to make sense of how it could be possible to believe a proposition $\mathrm{P}$ on the basis of the true proposition $\mathrm{P}$ itself. For now, the point of this discussion has primarily been to clarify what still needs to be done in order to defuse the Basing objection to the Self-Evidence principle (and also plausibly the No Guidance objection to the Truth-Norm of belief).

\section{Conclusion}

The Self-Evidence principle is a surprising convergent entailment of the prominent probabilistic and explanationist approaches to evidential support. Although it may be counterintuitive, the principle rationalises the practice of defending our claims by uncooperatively reasserting and reemphasising their truth. Even though it is unclear whether it is possible to believe a true proposition on the basis of this very true proposition, there are general reasons not to be too worried about potential problems arising from this. In particular, the popular and plausible Truth-Norm of Belief can be seen as a companion-in-guilt in this respect.

Self-Evidence is worth defending. On the one hand, since the principle is entailed by practically any probabilistic approach to evidential support, rescuing it from serious objections also saves the probabilistic approach from the threat of reductio ad absurdum. On the other, Self-Evidence provides the foundation for an attractive non-sceptical (and indeed, anti-sceptical) Williamsonian infallibilism about knowledge, where knowing a proposition entails that one's evidence guarantees that this proposition is true. ${ }^{44}$

Finally, although the principle may seem like a mere philosophical curiosity, it also has practical relevance for the prospect of doing epistemology in non-ideal political and social contexts. Some evidence (e.g., true propositions as evidence for themselves) can be rationally relied upon by individual agents and groups even though the evidence can never be cooperatively offered in a public exchange with those who disagree with the agent or group. Thus, there are dim prospects for a philosophical ideal of resolving deep disagreements by means of mere reasoning. However, there is also a positive upshot, which closely mirrors Amia Srinivasan's recent observations about the potential radical political significance of epistemological externalism in general. ${ }^{45}$ Knowers can rationally retain their knowledgeable beliefs just because they are true, even when these agents are surrounded by gaslighting and immersed in bad ideology. 46

\footnotetext{
${ }^{44}$ See Brown, Fallibilism, 3-9.

${ }^{45}$ Srinivasan, "Radical Externalism."

46 Many thanks to Tim Williamson for extensive feedback on this paper throughout its development. Thanks also to $\mathrm{Al}$ Prescott-Couch and a number of anonymous reviewers.
} 